\title{
Preparation of Perfective TAPO-5 Membrane through Tertiary Growth with Amorphous Seed
}

\author{
LIU Xu-Guang ${ }^{1}$, MA Xin ${ }^{1}$, LIU Yong ${ }^{1}$, ZHANG Bao-Quan ${ }^{1,2}$
}

(1. College of Materials Science and Engineering, Qingdao University of Science and Technology, Qingdao 266042, China; 2. State Key Laboratory of Chemical Engineering, School of Chemical Engineering and Technology, Tianjin University, Tianjin 300072, China)

\begin{abstract}
TAPO-5 membranes were synthesized through a tertiary growth method. Its perfection significantly depends on the adopted seed and itself poly-crystalline structure. Amorphous seed synthesized at a low crystallization temperature (393 K), obviously favors producing the perfective TAPO-5 membrane. TAPO-5 crystal seed, however, induces the growth of its membrane with a larger extent of cracks (i.e., grain boundary defect), destructing itself perfection. Those diverse results are associated with the disparate seeds layers deposited by a spreading-wetting method, and consistently demonstrated by SEM, XRD, and single gas (He) permeation test. A typical feature of the amorphous TAPO-5 seed layer is its dispersive distribution pattern in the macro holes of support. A continuous layer, however, is observed for the TAPO-5 crystal seed layer. The amorphous seed is explained as a prior seed for the perfective
\end{abstract} TAPO-5 membrane.

Key words: tertiary growth; amorphous seed; TAPO-5 membrane; spreading-wetting method

Aluminophosphate molecular sieves (AlPO- $n$ ), where $n$ denotes a particular structure type, have been recognized as a novel ordered microporous materials ${ }^{[1]}$. Their $\mathrm{AlPO}_{4}$ frameworks are rich of structural chemistry and special physiochemical properties of isomorphous substitution by heteroatoms ${ }^{[2]}$, like metal-aluminophosphate MAPO- $n$ $(\mathrm{M}=\mathrm{Ti}, \mathrm{Fe} \text {, etc })^{[3]}$. This enables them with excellent catalytic and separation properties. Typically, Ti incorporated AFI type aluminophosphate molecular sieve (TAPO-5, $\mathrm{T}=\mathrm{Ti}$ ) exhibits catalytic activities of selective oxidation, owning to its framework $\mathrm{Ti}$ as redox active centers ${ }^{[4]}$. TAPO-5, as well as TS- 1 membrane ${ }^{[5]}$, is of particular interests for possible applications as a catalytic or separation membrane. Its catalytic/separation membrane requires free of defects, i.e., no pinhole and cracks $^{[6]}$. Those defects will lead to short flow of reactants/feeds and fault catalytic/separation activities. Obtaining a high quality TAPO-5 membrane is critical to adopting it as the catalytic/separation membrane.

Available methods for preparing zeolite membranes include in-situ growth ${ }^{[7]}$, seeded growth ${ }^{[8]}$, and dry gel synthesis ${ }^{[9]}$. Among those methods, the seeded growth is widely used to prepare zeolite membranes, e.g., $\mathrm{AFI}^{[10]}$, $\mathrm{CHA}^{[11]}$, and $\mathrm{LTA}^{[12]}$, because of its preferable reproducibility $^{[13]}$. The quality of the membranes prepared by the seeded growth method is considerably affected by the seeding methods, including dip-coating ${ }^{[14]}$, rubbing ${ }^{[15]}$, vacuum seeding ${ }^{[16]}$, and filtration seeding ${ }^{[17]}$. Among these methods, the dip-coating method is easy to perform and generally adopted. The adopted seeds is paid few attentions. It depends on the crystalline nature of the seeds. Nano-sized crystals are popularly employed in the seeded growth. Amorphous seeds with a semi-crystal nature exhibits diverse induction behavior during the seed growth. This work will demonstrate that the amorphous seed is superior to the crystal seed in inducing the growth of the perfective TAPO-5 membrane. The as-synthesized TAPO- 5 membrane is activated by a mild method of catalytic hydrocracking ${ }^{[18]}$. Its template is hydrocracked to small molecules, its perfect structure being maintained.

\section{Experiments}

\subsection{Materials}

Phosphoric acid $\left(\mathrm{H}_{3} \mathrm{PO}_{4}, 85 \mathrm{wt} \%\right)$, pseudoboehmite $\left(\mathrm{Al}_{2} \mathrm{O}_{3}, 67 \mathrm{wt} \%\right.$, Aluminum Corporation of China, Ltd, Shandong Branch), and $\mathrm{TiOSO}_{4}$ were used as sources for phosphorus, aluminum, and titanium, respectively. Triethylamine (abbreviated as TEA) was chosen as the template 
for TAPO-5. These agents, except for pseudoboehmite, were all purchased from Sinopharm Chemical Reagent Co. Ltd. Homemade $\mathrm{SiO}_{2} / \alpha-\mathrm{Al}_{2} \mathrm{O}_{3}$ disc $\left(\mathrm{SiO}_{2}, 32 \mathrm{wt} \%\right.$, O.D. $=$ $20 \mathrm{~mm}^{[19]}$ ) was employed as supports for the TAPO-5 membrane.

\subsection{Synthesis of TAPO-5 seeds}

TAPO-5 seeds were synthesized via a solid-phase transformation method with a bath composition of $0.05 \mathrm{TiO}_{2}: 0.10 \mathrm{H}_{2} \mathrm{O}_{2}: 1.00 \mathrm{Al}_{2} \mathrm{O}_{3}: 1.10 \mathrm{P}_{2} \mathrm{O}_{5}: 1.50 \mathrm{TEA}: 25.00 \mathrm{H}_{2} \mathrm{O}$. Their preparation procedures were described as following. Phosphoric acid of $25.37 \mathrm{~g}$ weight was diluted with $18 \mathrm{~g}$ of ultrapure (UP) water and stirred for $10 \mathrm{~min}$. Pseudoboehmite of $15.22 \mathrm{~g}$ weight was slowly introduced into the diluted phosphoric acid under vigorously stirring. A homogeneous $\mathrm{Al}-\mathrm{H}_{3} \mathrm{PO}_{4}$ sol was obtained. This sol was dropped to an orange translucent $\mathrm{TiOSO}_{4}-\mathrm{H}_{2} \mathrm{O}_{2}$ aqueous solution, gained by dissolving $1.05 \mathrm{~g}$ of $\mathrm{TiOSO}_{4}$ in $1.13 \mathrm{~g}$ of $\mathrm{H}_{2} \mathrm{O}_{2}$ and diluted with $18 \mathrm{~g}$ of UP water. A yellow homogeneous Ti-Al- $\mathrm{H}_{3} \mathrm{PO}_{4}$ sol was obtained after stirring for $2 \mathrm{~h}$, and dropped with $15.18 \mathrm{~g}$ of TEA. This mixture was stirred for $1 \mathrm{~h}$ and aged overnight as a solid gel at room temperature. The resultant solid gel was loaded into a $50 \mathrm{~mL}$ Teflon autoclave and crystallized at $373-433 \mathrm{~K}$ for $24 \mathrm{~h}$. Solid products were centrifuged, washed, and dried at $333 \mathrm{~K}$.

\subsection{Preparation of TAPO-5 seed layers}

The spreading-wetting method, basing on a dip-coating route ${ }^{[14]}$, was typically performed as following. A seed ethanol suspension was prepared through dispersing a certain amount of the TAPO-5 seeds (synthesized at 393, 413, or $433 \mathrm{~K}$ ) in ethanol at $351 \mathrm{~K}$. The seed content was chosen to be $1 \mathrm{wt} \%$. The supports were dipped into those suspensions for $10 \mathrm{~s}$ and taken out. The seeded supports were dried at $353 \mathrm{~K}$ for $4 \mathrm{~h}$ and calcined at $823 \mathrm{~K}$ for $3 \mathrm{~h}$.

\subsection{Seeded growth of TAPO-5 membrane}

The seeded growth was executed from a precursor sol with a bath composition of $0.05 \mathrm{TiO}_{2}: 1.00 \mathrm{Al}_{2} \mathrm{O}_{3}: 1.10 \mathrm{P}_{2} \mathrm{O}_{5}$ : 1.50TEA: $105.00 \mathrm{H}_{2} \mathrm{O}: 0.10 \mathrm{H}_{2} \mathrm{O}_{2}$. This bath composition, with more water content, was prepared as the procedures of the TAPO- 5 seed. The resultant precursor sol of volume about $11 \mathrm{~mL}$ was loaded into a $50 \mathrm{~mL}$ Teflon lined autoclave. The seeded support was placed levelly on a homemade Teflon hold, with its seeded side facing down, and immersed in that precursor sol. The secondary growth was carried out at $433 \mathrm{~K}$ for $48 \mathrm{~h}$. After cooled to room temperature, the yield sample was removed out of the autoclave, washed with UP water, and dried at $333 \mathrm{~K}$ for overnight. They were utilized to a tertiary growth with the fresh precursor sol ${ }^{[20]}$. The resultant membranes were separated from that mother sol, washed, and dried at $333 \mathrm{~K}$ for overnight. Activating those membranes was achieved by a $\mathrm{Pd} / \mathrm{SiO}_{2}$ catalytic hydrocracking method performed as following ${ }^{[18]}$. The as-synthesized TAPO-5 membranes were loaded in the $\mathrm{Pd} / \mathrm{SiO}_{2}$ catalyst bed and heated to $593 \mathrm{~K}$ at $1 \mathrm{~K} / \mathrm{min}$, holding for $3 \mathrm{~h}$, in a hydrogen flow at $593 \mathrm{~K}$, before that test.

\subsection{Characterization}

X-ray diffraction (XRD) patterns were collected on a Rigaku D-MAX2500/PC X-ray diffractometer using $\mathrm{Cu}$ $K \alpha$ radiation. Scanning electron microscope (SEM) images were gained through scanning electron microscopy on a FEI Nanosem 430. Single gas (He) permeation of the TAPO-5 membranes was tested via transient permeation apparatus as described in the reference of [21]. The permeance $\left(f, \mathrm{~mol} /\left(\mathrm{m}^{2} \cdot \mathrm{s} \cdot \mathrm{Pa}\right)\right)$ is plotted as a function of varying average pressure $\left(P_{\mathrm{av}}\right)$ and fitted with a dusty-gas model $\left(f=\alpha+\beta \cdot P_{\mathrm{av}}\right.$, where permeability coefficients $\alpha$ and $\beta$ are attributed to Knudsen and viscous flow, respectively ${ }^{[22]}$ ).

\section{Results and discussion}

XRD (Fig. 1) and SEM (Fig. 2) characterization were utilized to reveal the crystal structure and morphology of the as-synthesized seeds crystallized at three temperatures (393, 413 and $433 \mathrm{~K}$ ), respectively. The seed crystallized at $393 \mathrm{~K}$ displays four extremely broad reflections centered at $2 \theta=15^{\circ}, 28^{\circ}, 38^{\circ}$, and $48^{\circ}$ in Fig. 1(a), indicating a semi-crystal nature. This seed, hereinafter, is claimed as an amorphous seed. Its semi-crystal nature led to an irregular morphology of nano size, as shown in Fig. 2(a). Another seed, crystallized at an elevated temperature of $413 \mathrm{~K}$, exhibits sharp diffraction peaks of an AFI structure, and some ambiguous peaks of aluminophospate (Fig. 1(b)). A certain amount of regular crystal thus is observed in Fig. 2(b). Employing a higher crystallization temperature of $433 \mathrm{~K}$ results in a well crystalized TAPO-5 with the AFI structure, verified by these sharp peaks $\left(2 \theta=7.4^{\circ}, 21.0^{\circ}, 22.5^{\circ}\right.$, and $25.9^{\circ}$, etc.) in Fig. 1(c). This seed shows a plate- like morphology with a thickness less than $150 \mathrm{~nm}$. Its

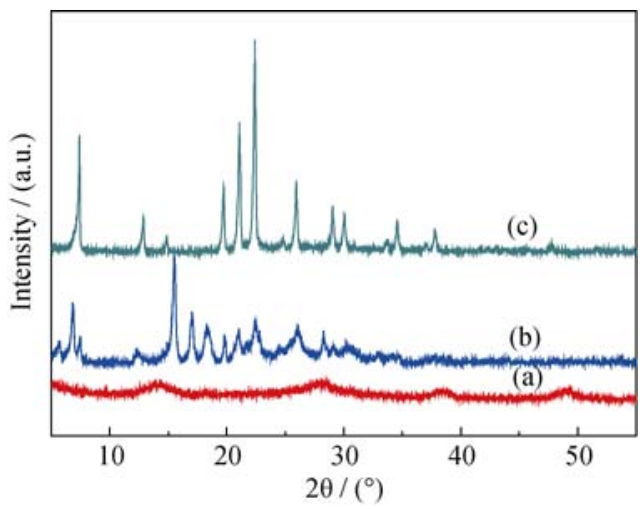

Fig. 1 XRD patterns of the as-synthesized TAPO-5 seeds crystallized at $393 \mathrm{~K}(\mathrm{a}), 413 \mathrm{~K}$ (b), and $433 \mathrm{~K}$ (c) 

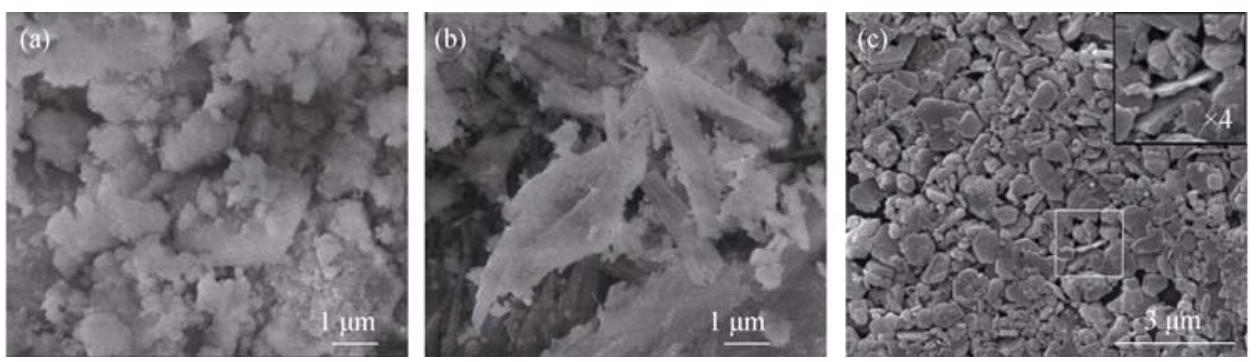

Fig. 2 SEM images of the as-synthesized TAPO-5 seeds crystallized at $393 \mathrm{~K}$ (a), $413 \mathrm{~K}$ (b) and $433 \mathrm{~K}$ (c)

high-aspect-ratio is estimated to be less than 0.2 , as comparable to the reported value $(0.3)$ of an available plate-like SAPO-5 seed ${ }^{[23]}$.

It is well known that amorphous or nano-sized zeolites exhibit high activity for inducing its membrane growth $^{[24]}$. Those seeds, crystallized at different temperatures (393, 413, and $433 \mathrm{~K}$ ), were utilized to deposit on $\mathrm{SiO}_{2} / \mathrm{Al}_{2} \mathrm{O}_{3}$ supports, and induced the growth of TAPO-5 membrane. The resulted seeds layers show distinguished XRD patterns (Fig. 3). There are obvious AFI peaks associated with the crystallized TAPO-5 seed layer (Fig. 3(c)), depositing the seed crystallized at $433 \mathrm{~K}$. Both XRD patterns of the seed layers (Fig. 3(a), (b)), deposited the seeds crystallized at $393 \mathrm{~K}$, or $413 \mathrm{~K}$, does not show any diffraction peaks due to the AFI pattern. This is attributed to few of the amorphous TAPO-5 seeds deposited on the support.

Presence of those seeds and the toughness bare support, however, was confirmed by SEM characterization (Fig. 4). It is seen that these seeds layers show diverse distributions on supports. Most of the amorphous seed are well dispersed in the macro holes of toughness support. For the seeded support with the seed crystallized at $413 \mathrm{~K}$, some of the nano particles were similarly distributed in the macro holes of support, while some of the large particles were located on the surface of support. The crystallized plate-like TAPO-5 seed, synthesized at $433 \mathrm{~K}$, almost remained on the support's surface as a continuous layer with plenty of pinholes. Those distinguish seeds distributions may cause different growth behaviors and the quality of zeolite membrane ${ }^{[25]}$.

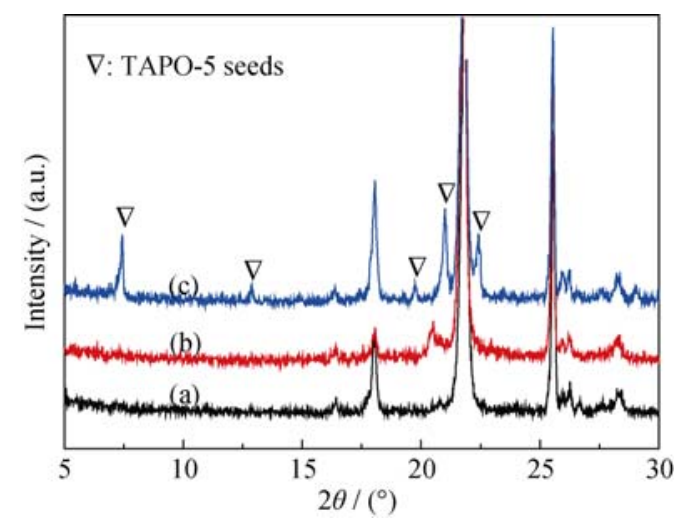

Fig. 3 XRD patterns of the seeded supports with TAPO- 5 seeds crystallized at $393 \mathrm{~K}$ (a), $413 \mathrm{~K}$ (b) and $433 \mathrm{~K}$ (c)
Those seeded supports were performed a tertiary growth for TAPO-5 membranes. The resultant TAPO-5 membranes all exhibit typical XRD patterns owning to AFI type crystal (Fig. 5). These peaks, due to different crystal surfaces, indicate non-oriented growth of the TAPO-5 membrane. This phenomenon is obviously diverse to epitaxial growth of oriented AFI membrane on seeded smooth supports ${ }^{[20,23]}$. It is worth noting a more possible choose of that toughness support in practice. The TAPO- 5 membrane, however, may not in-situ growth on the bare support ${ }^{[9]}$.

Those non-oriented TAPO-5 membranes are shown through SEM images in Fig. 6. They exhibit a continuous ploy-crystalline structure with some cracks (i.e., grain boundary defects), whatever the seeds are adopted. These cracks, destructing the perfection of the membranes, were formed in response to thermal tensile stresses ${ }^{[6]}$. Their extent, however, associates with the adopted seeds, as seen from those SEM images. A little extent of that crack is observed for the TAPO-5 membrane seeded by the amorphous seed. A much larger extent of the crack presences in the TAPO- 5 membrane seeded by the TAPO- 5 crystal. That crack is noted in the cross sectional images (Fig. 6(i)), also illustrating the non-oriented ploy-crystalline structure with a thickness of 18-20 $\mu \mathrm{m}$. It is not observed in Fig. 6(c)
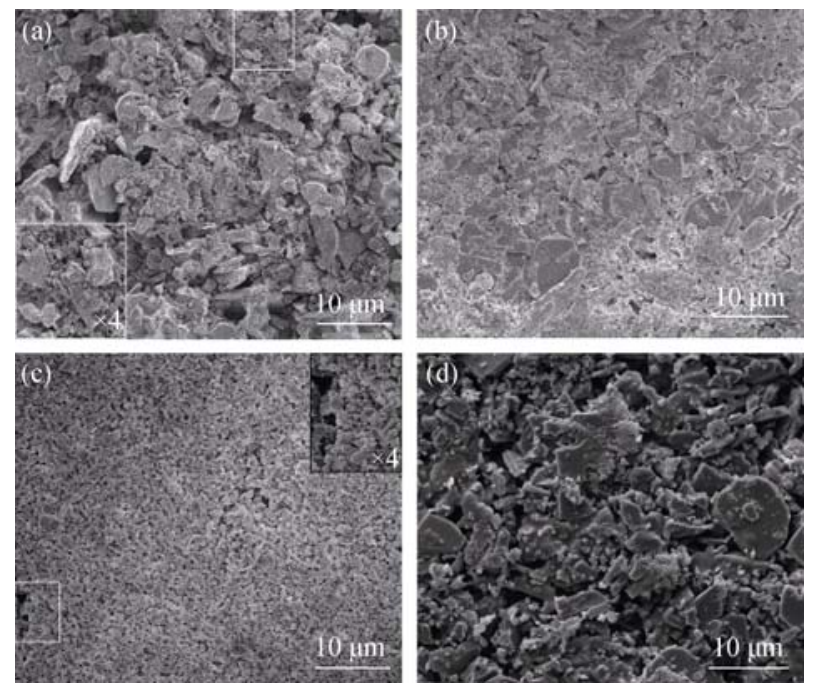

Fig. 4 SEM images of the seeded supports with TAPO-5 seeds crystallized at 393 (a), 413 (b), $433 \mathrm{~K}$ (c), and bare support (d) 


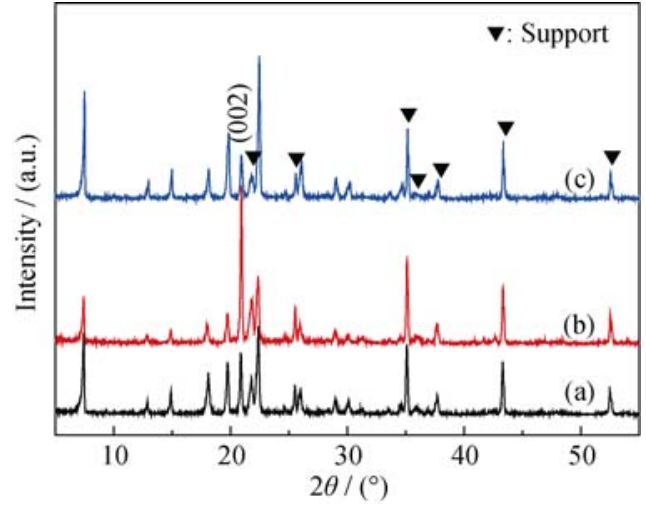

Fig. 5 XRD patterns of the TAPO-5 membranes, which seeds are synthesized at $393 \mathrm{~K}$ (a), $413 \mathrm{~K}$ (b) and $433 \mathrm{~K}$ (c)

of the TAPO-5 membrane seeded by the amorphous seed. Another focus is incorporating Ti into the framework of TAPO-5 membranes, as revealed by UV-vis spectra in Fig.7. Similar strong absorbtion bands between 200$300 \mathrm{~nm}$, ascribed to charger transfer of the framework $\mathrm{Ti}^{[3,9]}$, suggest negligible diverse in micro structure associated with Ti.

These seeds, with different crystallinity, obviously brings about distinguish hetero epitaxial growth behaviors of the TAPO-5 membrane on the support, and thus the diverse perfection proved by single gas permeation associated ${ }^{[22]}$.
He permeance of the as-synthesized TAPO-5 membrane, seeded with the amorphous seed, was measured o be less than $1 \times 10^{-10} \mathrm{~mol} /\left(\mathrm{m}^{2} \cdot \mathrm{s} \cdot \mathrm{Pa}\right)$, verifying its perfection. He permeance of the as-synthesized TAPO-5 membranes, synthesized with the crystal seeds, were more than $1 \times 10^{-7} \mathrm{~mol} /\left(\mathrm{m}^{2} \cdot \mathrm{s} \cdot \mathrm{Pa}\right)$ before activation, suggesting those defective membranes. Aftertactivated by the $\mathrm{Pd} / \mathrm{SiO}_{2}$ catalytic hydrocracking method performed at $593 \mathrm{~K}$, these membrane are tested for the He permeance and fitted with a dusty-gas model (Fig. 8). The permeance of the activated TAPO-5 membrane, seeded with the amorphous seed, is noticeably lower than those of the TAPO-5 membrane seeded with the crystals. A much smaller viscous flow coefficient (0.004) of the former TAPO-5 membrane indicates negligible defects. Both larger viscous flow coefficients (1.340 and 3.120) for the later membranes prove the grain boundary defects as revealed by the SEM images.

Those results illustrate priority of the amorphous seed on synthesizing the perfective TAPO-5 membrane. This may be associated with its high activity for inducing the inter-grown of TAPO- 5 crystal and forming the polycrystalline structure ${ }^{[24]}$. Another possible promotional effect is the dispersive distribution of the amorphous seeds in the holes of supports ${ }^{[25]}$.
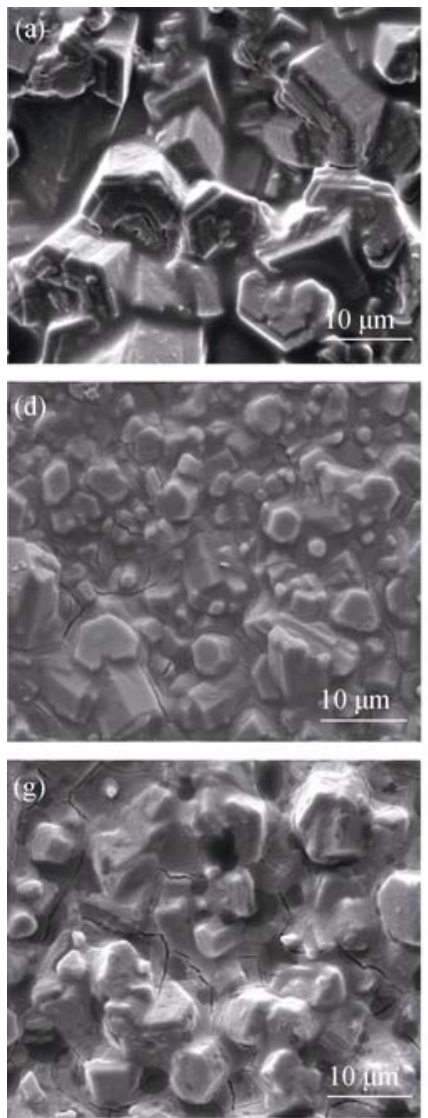
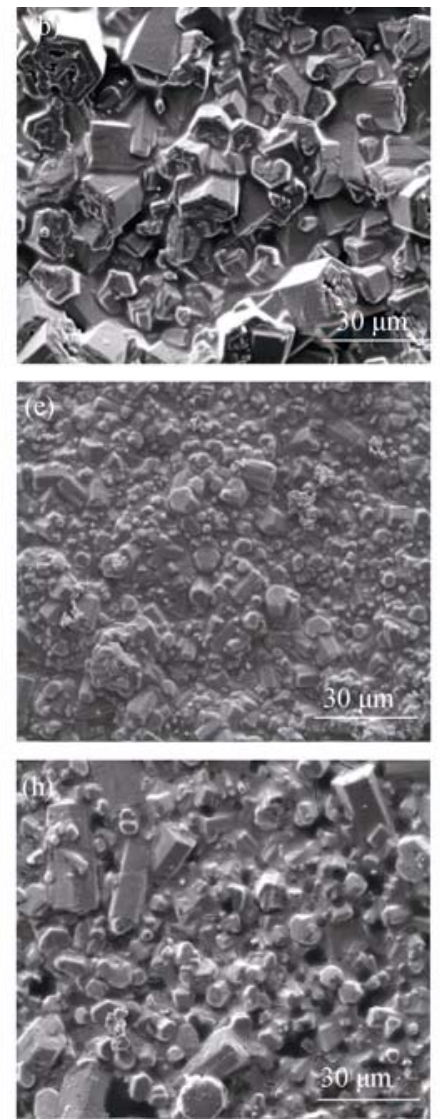
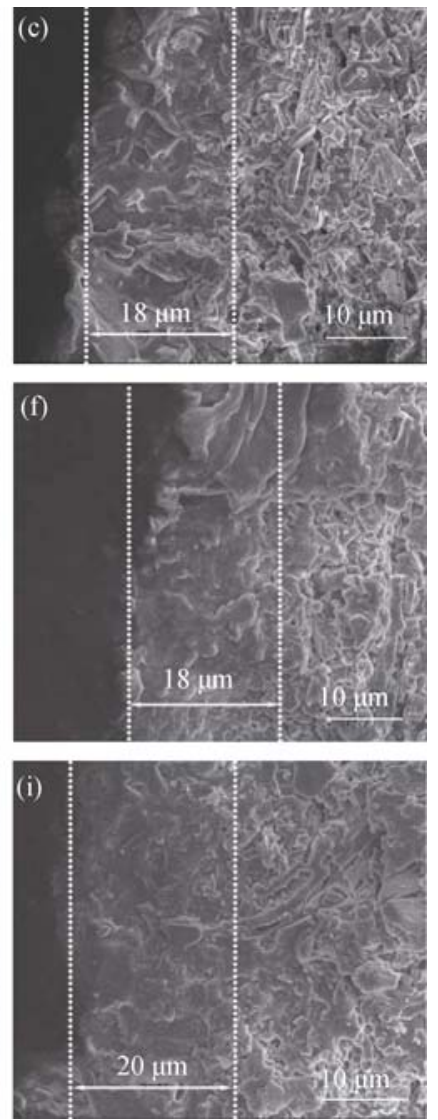

Fig. 6 Surface and cross sectional SEM images of the TAPO-5 membranes, whose seeds are synthesized at $393 \mathrm{~K}$ (a, b, c), $413 \mathrm{~K}$ (d, e, f) and $433 \mathrm{~K}(\mathrm{~g}, \mathrm{~h}, \mathrm{i})$ 


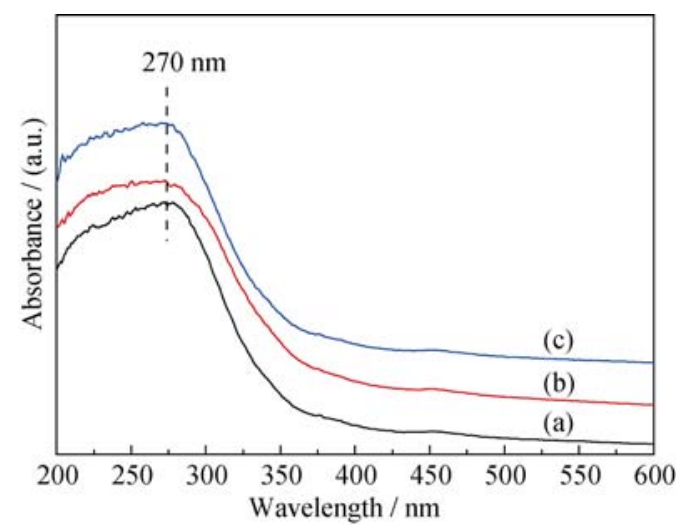

Fig. 7 UV-Vis diffuse reflection spectra of TAPO-5 membranes, which seeds are synthesized at $393 \mathrm{~K}$ (a), $413 \mathrm{~K}$ (b) and $433 \mathrm{~K}$ (c)

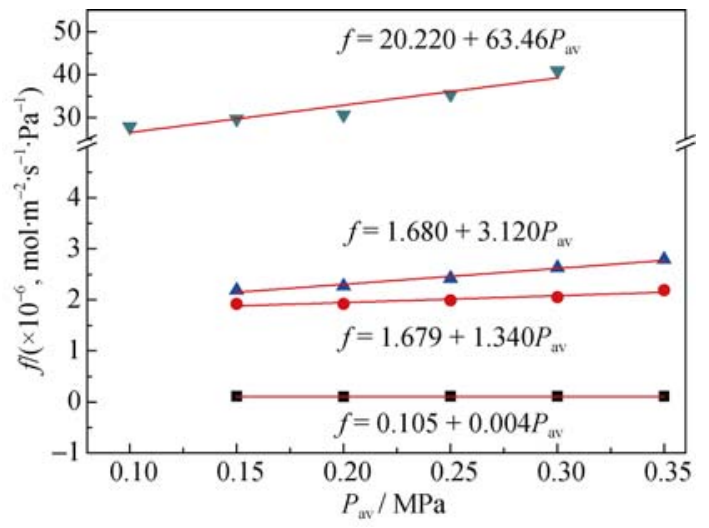

Fig. 8 He permeance of the bare support $(\boldsymbol{\nabla})$ and TAPO-5 membranes, whose seeds are synthesized at $393 \mathrm{~K}(\boldsymbol{\bullet}), 413 \mathrm{~K}(\bullet)$ and $433 \mathrm{~K}(\mathbf{\Delta})$

\section{Conclusions}

TAPO-5 seeds were synthesized at different crystallization temperature. Amorphous seed was obtained at the crystallization temperature of $393 \mathrm{~K}$, while a crystallized TAPO- 5 seed was synthesized at $433 \mathrm{~K}$. Whatever kind of those seeds are feasible to induce the growth of the TAPO-5 membrane, as proved by the XRD characterization. The former amorphous seed, but the later crystal seed, was beneficial to obtain crack-free TAPO-5 membrane. This behavior is associated with the disparate seeds layers deposited by the spreading-wetting method, and consistently illustrated by the SEM images and single gas permeation. The amorphous seed thus is a prior choice to prepare the perfective TAPO-5 membrane via the tertiary growth.

\section{References:}

[1] YU J H, XU R R. Rich structure chemistry in the aluminophosphate family. Accounts of Chemical Research, 2003, 36(7):
481-490.

[2] ZHAO X H, LI X B, CHEN J, et al. Ambient pressure synthesis of hierarchical structured SAPO-5 molecular sieve with special morphology. Journal of Inorganic Materials, 2014, 29(8): 821-826.

[3] SARA M, MUTHUSAMY V, MARIO C, et al. Elucidating the nature and reactivity of $\mathrm{Ti}$ ions incorporated in the framework of $\mathrm{AlPO}_{4}-5$ molecular sieves. New evidence from ${ }^{31} \mathrm{P}$ HYSCORE spectroscopy. Journal of the American Chemical Society, 2011, 133(19): 7340-7343.

[4] LEE S O, RAJA R, HARRIS K D M, et al. Mechanistic insights into the conversion of cyclohexene to adipic acid by $\mathrm{H}_{2} \mathrm{O}_{2}$ in the presence of a TAPO-5 catalyst. Angewandte Chemie International Edition, 2013, 42(13): 1520-1523.

[5] WANG X B, GUO Y, ZHANG X F, et al. Catalytic properties of benzene hydroxylation by TS- 1 film reactor and Pd-TS-1 composite membrane reactor. Catalysis Today, 2010, 156(3/4): 288-294.

[6] CHOI J, JEONG H-K, SNYDER M A, et al. Grain boundary defect elimination in a zeolite membrane by rapid thermal processing. Science, 2009, 325(5940): 590-593.

[7] YANG W S, ZHANG B Q, LIU X F. Synthesis and characterization of SAPO-5 membranes on porous $\alpha-\mathrm{Al}_{2} \mathrm{O}_{3}$ substrates. Microporous and Mesoporous Materials, 2009, 117(1/2): 391-394.

[8] WANG X D, YAN J, HUANG W. Preparation and characterization of ultrafine crystal TS-1 films. Journal of Inorganic Materials, 2011, 26(1): 85-90.

[9] WANG J F, LIU X G, ZHANG P P, et al. Synthesis of continuous and dense TAPO-5 molecular sieve membranes by steam-assisted gel conversion method. Journal of Inorganic Materials. 2013, 28(6): 589-593.

[10] STOEgER J A, PALOMINO M, AGRAWAL K V, et al. Oriented CoSAPO-5 membranes by microwave-enhanced growth on $\mathrm{TiO}_{2}$ coated porous alumina. Angewandte Chemie International Edition, 2012, 51(10): 2470-2473.

[11] CARREON M A, LI S, FALCONER J L, et al. Alumina-supported SAPO-34 membranes for $\mathrm{CO}_{2} / \mathrm{CH}_{4}$ separation. Journal of the American Chemical Society, 2008, 130(16): 5412-5413.

[12] HUANG A, CARO J. Highly oriented, neutral and cation-free $\mathrm{AlPO}_{4}$ LTA: from a seed crystal monolayer to a molecular sieve membrane. Chemical Communications, 2011, 47(14): 4201-4203.

[13] SATO K, NAKANE T. A high reproducible fabrication method for industrial production of high flux NaA zeolite membrane. Journal of Membrane Science, 2007, 301(1/2): 151-161.

[14] DAS J K, DAS N, BANDYOPADHYAY S. Highly oriented improved SAPO-34 membrane on low cost support for hydrogen gas separation. Journal of Materials Chemistry A, 2013, 1(16): 
$4966-4973$.

[15] ZHOU M, HEDLUND J. Assembly of oriented iron oxide and zeolite crystals via biopolymer films. Journal of Materials Chemistry, 2012, 22(47): 24877-24881.

[16] HUANG A, LIN Y S, YANG W. Synthesis and properties of A-type zeolite membranes by secondary growth method with vacuum seeding. Journal of Membrane Science, 2004, 245(1/2): $41-51$.

[17] ALGIERI C, BERNARDO P, BARBIERI G, et al. A novel seeding procedure for preparing tubular $\mathrm{NaY}$ zeolite membranes. Microporous and Mesoporous Materials, 2009, 119(1/2/3): 129-136.

[18] LIU X G, XU L, ZHANG B Q, et al.Template removal from AFI aluminophosphate molecular sieve by $\mathrm{Pd} / \mathrm{SiO}_{2}$ catalytic hydrocracking at mild temperature. Microporous and Mesoporous Materials, 2014, 193:127-133.

[19] CHEN S B, LIU X G, ZHANG B Q. Preparation and properties of porous $\alpha-\mathrm{Al}_{2} \mathrm{O}_{3}$ based ceramic disk substrates. Journal of Inorganic Materials, 2013, 28(6): 599-604.

[20] KARANiKOlOS G N, WYDRA J W, STOEGER J A, et al. Con- tinuous $c$-oriented $\mathrm{AlPO}_{4}-5$ films by tertiary growth. Chemistry of Materials, 2007, 19(4): 792-797.

[21] LANG L, LIU X F, ZHANG B Q. Synthesis and characterization of $(h 0 h)$-oriented silicalite-1 films on $\alpha-\mathrm{Al}_{2} \mathrm{O}_{3}$ substrates. Appllied Surface Science, 2008, 254(8): 2353-2358.

[22] KANEZASHI M, O'BRIEN J, LIN Y S. Template-free synthesis of MFI-type zeolite membranes: permeation characteristics and thermal stability improvement of membrane structure. Journal of Membrane Science, 2006, 286(1/2): 213-222.

[23] HU E P, HUANG Y L W, YAN Q, et al. Synthesis of highly $c$-oriented AFI membranes by epitaxial growth. Microporous and Mesoporous Materials, 2009, 126(1/2): 81-86.

[24] KARANIKOLOS G N, GARCIA H, CORMA A, et al. Growth of $\mathrm{AlPO}_{4}-5$ and CoAPO-5 films from amorphous seeds. Microporous and Mesoporous Materials, 2008, 115(1/2): 11-22.

[25] PENG Y, ZHAN Z Y, SHAN L J, et al. Preparation of zeolite MFI membranes on defective macroporous alumina supports by a novel wetting-rubbing seeding method: role of wetting agent. Journal of Membrane Science, 2013, 444: 60-69.

\title{
无定形晶种引导三次生长制备完备性 TAPO-5 膜
}

\author{
刘旭光 ${ }^{1}$ ，马㸝 ${ }^{1}$ ，刘 勇 ${ }^{1}$, 张宝泉 ${ }^{1,2}$
}

(1. 青岛科技大学 材料科学与工程学院, 青岛 266042; 2. 天津大学 化工学院, 化学工程国家重点实验室, 天津 300072)

摘 要: TAPO-5 膜可以通过三次生长法制备。它的完备性与所用晶种以及膜的多晶结构密切相关。 $393 \mathrm{~K}$ 下晶化所得 无定形晶种有利于引导制备完备性 TAPO-5 膜。然而, 晶态 TAPO-5 晶种引导制备的 TAPO-5 膜存在大量的裂纹(即晶 界缺陷), 这破坏了膜的完备性。这些不同结果可以通过 SEM、XRD 和单组分气体渗透(He)测试进行说明。它与铺展 润湿法所形成的晶种层的不同形式有关。无定形晶种层的典型特征是晶种分散于载体的大孔缺陷中。然而, 晶态 TAPO-5 将以连续晶种层的形式存在。因此, 无定形晶种更适合引导制备完备性 TAPO-5 膜。

关 键 词: 三次生长; 无定形晶种; TAPO-5 膜; 铺展润湿法

中图分类号: TQ174

文献标识码: A 